February 2007

\title{
Convenient care clinics: The future of accessible health care
}

Tine Hansen-Turton

National Nursing Centers Consortium, Philadelphia

Sandra Ryan

Take Care Health Systems, Conshohocken

Ken Miller

American Academy of Nurse Practitioners and Pennsylvania State University

Mona Counts

American Academy of Nurse Practitioners and Pennsylvania State University

David B. Nash

Thomas Jefferson University

Follow this and additional works at: https://jdc.jefferson.edu/healthpolicyfaculty

Part of the Health Services Research Commons

Let us know how access to this document benefits you

\section{Recommended Citation}

Hansen-Turton, Tine; Ryan, Sandra; Miller, Ken; Counts, Mona; and Nash, David B., "Convenient care clinics: The future of accessible health care" (2007). College of Population Health Faculty Papers. Paper 32.

https://jdc.jefferson.edu/healthpolicyfaculty/32

This Article is brought to you for free and open access by the Jefferson Digital Commons. The Jefferson Digital Commons is a service of Thomas Jefferson University's Center for Teaching and Learning (CTL). The Commons is a showcase for Jefferson books and journals, peer-reviewed scholarly publications, unique historical collections from the University archives, and teaching tools. The Jefferson Digital Commons allows researchers and interested readers anywhere in the world to learn about and keep up to date with Jefferson scholarship. This article has been accepted for inclusion in College of Population Health Faculty Papers by an authorized administrator of the Jefferson Digital Commons. For more information, please contact: JeffersonDigitalCommons@jefferson.edu. 


\title{
Convenient Care Clinics: The Future of Accessible Health Care
}

\author{
TINE HANSEN-TURTON, M.G.A., ${ }^{1}$ SANDRA RYAN, M.S.N., C.P.N.P., ${ }^{2}$ \\ KEN MILLER, Ph.D., C.R.N.P., F.A.A.N., ${ }^{3}$ MONA COUNTS, Ph.D., C.R.N.P., ${ }^{4}$ \\ and DAVID B. NASH, M.D., M.B.A. ${ }^{5}$
}

\begin{abstract}
The need for accessible, affordable, quality health care in the United States has never been greater. In response to this need, convenient care clinics (CCCs) are being launched across the country to help provide care to meet the basic health needs of the public. In CCCs, highly qualified health care providers diagnose and treat common health problems, triage patients to the appropriate level of care, advocate for a medical home for all patients, and reduce unnecessary visits to emergency rooms and Urgent Care Clinics. CCCs have been called a "disruptive innovation" because they are consumer driven. They serve as a response to many patients who are unhappy with the current conventional health care delivery system-a system that is challenged to provide access to basic health care services when people need it the most. CCCs are based in retail stores and pharmacies. They are primarily staffed by nurse practitioners (NPs). Some CCCs are staffed by physician assistants (PAs) and physicians. The authors acknowledge the important roles of both PAs and physicians in CCCs; however, this paper primarily provides education about the role of NPs in CCCs. CCCs have evolved at a time when our health care system is floundering, and the need for accessible, affordable health care is at its greatest. The CCC model provides an accessible, affordable entry point into the health care system for those who previously were restricted access. (Disease Management 2007;10:61-73)
\end{abstract}

\section{INTRODUCTION}

$\mathbf{T}$ HE NEED FOR ACCESSIBLE, affordable, quality health care in the United States has never been greater. In response to this need, convenient care clinics (CCCs) are being launched across the country to help provide care to meet the basic health needs of the public. These health care clinics, based in retail stores and pharmacies, are staffed primarily by nurse practitioners (NPs) and provide care for patients with and without insurance. Physician

\footnotetext{
${ }^{1}$ National Nursing Centers Consortium, Philadelphia, Pennsylvania.

${ }^{2}$ Take Care Health Systems, Conshohocken, Pennsylvania.

${ }^{3}$ American College of Nurse Practitioners, and University of New Mexico College of Nursing, Albuquerque, New Mexico.

${ }^{4}$ American Academy of Nurse Practitioners, and Pennsylvania State University School of Nursing, University Park, Pennsylvania.

${ }^{5}$ Department of Health Policy, Jefferson Medical College, Philadelphia, Pennsylvania.
} 
assistants (PAs) and physicians also staff CCCs; however, this paper primarily focuses on the role of NPs in CCCs. CCC providers are experienced and highly educated health care professionals who deliver high-quality, patientcentered care. Health care driven by the needs of the patient is at the heart and soul of the Convenient Care Industry (CCI).

Over the past year, the media has extensively covered the emergence of retail-based CCCs. Many have written about the expectation that retail health clinics will "profoundly affect health care delivery by providing an alternative site for basic medical needs." ${ }^{1}$ CCC s have been called a "disruptive innovation" because they are consumer driven and they serve as a response to many health care patients who "are frustrated with the conventional health care delivery system," which provides little access to basic health care services when people need it the most. ${ }^{2}$ While the CCI still has yet to fully establish itself, the clinics have shown tremendous potential in providing affordable, accessible, and quality health care to consumers who otherwise would have to wait hours, days, or even weeks for the care they deserve. Other alternatives include seeking costly, time-consuming emergency room care for illnesses that could have been prevented if basic health care services had been accessible.

Ownership of CCCs varies; some are privately held, and others are run by health systems or non-profit organizations. Most have a medical director involved at the highest level of the organization, and some have nursing leadership. Several of the leading CCCs have a medical and a NP officer who work collaboratively to oversee the medical scope of practice and quality care of the organization.

In addition to highly qualified PAs and physicians, CCCs are usually staffed by Family Nurse Practitioners (FNPs), who provide high-quality health care services for episodic, common family ailments. Services include diagnosis and treatment of the most common health problems experienced by patients, including sore throats, immunizations, and preventive health care screenings. Evidence to date has shown that "clinics do not increase overall demand for medical services, an initial concern expressed by the medical and insur- ance community; rather, they offer an alternative for consumers [at all socioeconomic levels] facing access problems within the conventional health care system." ${ }^{2}$ To date, consumers have expressed high levels of satisfaction with the services provided by NPs, PAs, and physicians in CCCs, as well as the convenience of the CCC model.

The CCI plans to expand across the nation, establishing thousands of clinics over the next few years and ultimately increasing access for all Americans. CCI leaders are determined to ensure that the convenient care movement is recognized as one of high quality and integrity. Thus, in the summer of 2006, leaders and stakeholders of the new and emerging retail-based CCI convened a Summit to shape the future of this new industry. At the Summit, participants presented information about CCCs and NPs as providers of care. The information, data, and input from Summit participants have resulted in this paper, the purpose of which is to provide background and historical information on the industry, to explain the role that NPs play in CCCs, to describe the role of the new consumer-driven model of care, and to identify future directions for the CCI.

\section{HISTORY AND BACKGROUND OF THE CCC MODEL}

While CCCs are a relative new provider type in the United States, the concept of highly trained nurses as independent care providers dates as far back as the 1890s, when visionaries such as Lillian Wald founded the Henry Street Settlement; later, Margaret Sanger opened the first birth control clinic. CCCs are following in the footsteps of independent nurse-managed health centers, in which a nurse occupies the chief management position, accountability and responsibility for client care and professional practice remain with nursing staff, and NPs are the primary providers seen by clients. ${ }^{3}$ CCCs began in 2000, when the first in-store clinics, operated by QuickMedx, appeared in Minneapolis-St. Paul. These first clinics initially saw a very limited number of illnesses and accepted only cash for services. Today there are over a dozen companies across 
the country that provide health care services to individuals and families for common illnesses. A 2005 Wall Street Journal Online Interactive Health-Care Poll showed that $83 \%(n=2245)$ of those polled strongly or somewhat agree that companies can provide on-site health services at retail stores, and that $78 \%(n=2245)$ felt strongly that retail-based clinics provide a convenient way for people to receive basic medical services. ${ }^{4}$

There are an estimated 200 CCCs throughout the United States today. The clinics are conveniently located in drug stores, food stores, and other retail settings with pharmacies, enabling patient accessibility, and making it easy and convenient for patients to get their prescriptions filled on site. Therefore, it seemed suitable to call this revolution in health care delivery the "Convenient Care Industry."

CCCs range in size from one exam room to multiple exam rooms with sinks and exam tables. The clinics generally occupy 200-500 square feet and are outfitted with all the necessities of an outpatient health care office. Federal laws require that owners and operators of the clinics rent retail space at fair market value. The NPs who staff CCCs work for the clinic operators and have a collegial relationship with the pharmacy staff of the retail setting. The average cost to set up a clinic is approximately $\$ 75,000$, excluding payroll and corporate overhead costs. Most of the clinics are open seven days a week-twelve hours a day during the workweek and eight hours on Saturday and Sunday. These hours are generally more convenient than those of a traditional doctor or primary care provider (PCP) office. The clinics are usually busier on the weekends, in the evening, and at lunchtime, reflecting their convenience and consumer focus. Most of the clinics see patients 18 months of age and older, and visits generally take 15-25 minutes for diagnosis and treatment. CCCs believe strongly in the transparency of medical costs; thus, the clinics post the health care services offered, treatment costs, and information on NPs as providers of care. The basic cash cost for a visit to a CCC ranges from $\$ 40$ to $\$ 70$. Additional charges may be assessed for diagnostic screenings and immunizations. Many insurance plans cover visits to CCCs, allowing the patient to pay only a co-pay.
The clinics are staffed by NPs, and in some cases PAs or physicians affiliated with a corporate entity. The NPs and/or PAs (and in some instances physicians) provide all medical care and also handle some administrative functions. Some CCCs also have medical assistants who aid the NPs or physicians and help with patient flow. Most care clinics use proprietary software systems, electronic health records (EHRs), and technology to enhance the patient experience and continuity of care within the medical community. In general, CCCs have written guidelines and established protocols that providers use to assist with their decisionmaking process and to ensure the highest level of patient care and satisfaction. For example, when patients arrive at a clinic, they sign in and provide basic demographic information and the reason for their visit, sometimes using a touch-screen computer terminal (similar to an airline self-check-in kiosk). This sign-in process is the beginning of the patient's EHR. In some cases, this information is then immediately transmitted to a computer terminal inside the treatment room, where a NP is notified that a patient is waiting to be seen. Once the patient is escorted to the exam room, the NP validates the information provided by the patient at signin and enters additional medical information about the patient's symptoms and conditions, as well as any pertinent medical history.

NPs perform Clinical Laboratory Improvement Amendments (CLIA)-waived lab tests, write prescriptions if needed, and transmit prescriptions to the store pharmacy or any pharmacy that accepts electronic scripts. Or, if the patient prefers, a printed script can be provided at the conclusion of the visit for fulfillment at any pharmacy. To ensure continuity of care, patients are given copies of their health records at the end of the visit, which they then are able to share with their primary health care provider or any other member of the health care team. In many cases, CCC operators simply make the patients' Personal Health Records available to their PCPs, referral physicians, or hospitals, pending patient request and approval. This information also can be faxed to any provider that the patient designates to further enhance the continuity of care process. At this time, records cannot be e-mailed due to the 
unsecured method of transmission. However, the longer-term goal is to exchange the patient's EHR with the provider the patient authorizes. As CCCs continue to work with physicians and other health care providers, and as relationships and technologies develop, safe and secure electronic sharing of records will become more standard and common. In turn, patients will be able to access their health records online.

Many physicians across the nation have partnered with CCCs in providing a collaboration and referral network system for patients who come to the clinics. Many of these physicians welcome CCCs as an alternative for their patients. However, some medical groups opposed the formation of CCCs, basing their objection on the fear that patients would not receive quality care or get integrated health care, and that NPs were not qualified or suited to work in an independent setting. However, others believed that the creation of CCCs was spurred by patients' desire for more convenient, affordable health care, and that CCCs represent a needed alternative for access to health care for patients.

To date, the American Academy of Family Physicians, the American Medical Association, and the American Academy of Pediatrics have responded to the formation of the CCI by calling for increased regulation of the practice and industry. They have published principles and guidelines in an attempt to regulate CCI operations and to address the quality of care delivered. ${ }^{5}$ The American College of Nurse Practitioners, meanwhile, has adopted a resolution in support of the CCI and its role in improving access to care. The CCI welcomes the input of such organizations and will work in collaboration with them to foster quality of care and accessibility within the delivery system. Several CCCs have reached out to the greater medical and nursing community to encourage their participation in a meeting on access, integration, and most importantly, how they can unite to serve the needs of patients. The demand for this new model of care arises from an urgent issue recognized by many across the entire spectrum of healthcare providers-that of access to care. There is a critical need for continued dialogue between the CCI and the medical/nursing community. The CCI looks forward to working with medical and nursing organizations and the local communities in which they operate to ensure integrated patient care and the delivery of a quality patient healthcare experience.

\section{HISTORY, SCOPE OF PRACTICE, AND ROLE OF NPS IN THE UNITED STATES}

In a recent Pennsylvania policy paper, advocates argued that a highly trained cadre of health care professionals, advanced practice nurses (APNs), is positioned to significantly expand the capacity of the health care delivery system. ${ }^{6}$ APNs work in a variety of settings (eg, urban and rural, private and public) and are more likely than PCPs to work in underserved areas. ${ }^{7}$ Within the profession of nursing, there are four advanced practice providers: Certified Registered Nurse Practitioner, Certified NurseMidwife, Clinical Nurse Specialist, and Certified Registered Nurse Anesthetist. Unlike the traditional hospital nurse who works under orders of a physician, APNs work relatively independently in accordance with state laws. To understand the business model of the CCI, it is necessary to also understand the history and scope of practice of its main health care provider, the NP.

Independent nursing practice initially developed in areas where physicians had not yet established their field, such as nurse-midwifery and anesthesia, and usually outside mainstream settings, such as in rural areas. ${ }^{8}$ The evolution in nursing education and, ultimately, advanced nursing practice took off after the Second World War. Nurses who had practiced in the war left the service with officer rank and, through the G.I. Bill, used federal funding to attend college to obtain basic and advanced practice nursing degrees. ${ }^{8}$ Around the same time, visiting and public health nurses expanded their reach in communities and began to manage clinics, school-based care, and home care. ${ }^{8}$ Further, in the 1960s, nurse and physician collaborative teams began to practice in places such as Colorado and Rochester, New York. ${ }^{8}$ The passage of the 1965 Medicare and Medicaid legislation created a new demand for health care services. There was an inadequate 
supply of physicians to meet the demand, which gave nurses an opportunity to go into primary care and develop a new provider type, the NP. 8

Simultaneously, organized consumer groups, women, and civil rights activists demanded a new level of more accessible and affordable health care. Nursing claimed that it had the history, education, organization, and knowledge to meet the growing primary care demands of these groups. ${ }^{8}$ Thus, NPs evolved from nursing's potential, society's needs, and a PCP shortage. ${ }^{8}$

Loretta Ford, a nursing professor, and Henry Silver, a pediatrician, established the first NP program at the University of Colorado in $1965 .{ }^{8}$ The program was based on a "nursing model focused on the promotion of health in daily living, growth and the development for children in families as well as the prevention of disease and disability." 9 In the late 1960s, other schools of nursing followed suit and started NP programs. Because the idea of NPs came at a time in history when there was a concern about consumer accessibility and affordable care, it won overall support from the general community, although less support from the professional medical community. ${ }^{8}$ In 1984, the Institute of Medicine's Committee on the Future of Primary Care defined primary care as "the provision of integrated, accessible health care service by clinicians who are accountable for addressing a large majority of personal health care needs, developing a sustained partnership with patients, and practicing in the context of family and community." 10 This definition broadened the scope of primary care and supported the continued educational growth of NPs.

"NPs may perform any service authorized by a state practice act." 11 Generally, NPs can obtain medical histories; perform physical examinations; diagnose and treat health problems; order and interpret laboratory tests and x-rays; prescribe medications and treatments; provide prenatal care and family planning services, well-child care and immunizations, and gynecological examinations and pap smears; provide education about health risks, health promotion, illness prevention and health maintenance; and provide case management and coordination of service. It is the combination of skills of physician and nurse that seems to con- fuse people about the role of NPs, 12 "yet it is that combination of skills that makes an NP unique" and attractive to the new CCI groups.* The expansive duties and responsibilities of these health care providers is evidence of the diverse and comprehensive competencies of NPs, and illustrates why NPs have become popular providers for physicians, who hire them in their practices to supplement their care; for hospitals; for freestanding nurse-managed health centers; and now for CCIs that recognize their value in providing accessible health care.

In 2004, there were 196,279 APNs; 141,000 of this number were NPs. ${ }^{13}$ While advanced practice nursing was not initially at the master's de-

*In a typical primary care setting (such as a nurse-managed health center and not a convenient care center), a NP conducts comprehensive medical and social histories of individuals, including healthy patients and those with acute illnesses and chronic diseases; conducts physical examination of individuals; orders, performs, and interprets laboratory tests for screening and diagnosing; prescribes medications; performs therapeutic or corrective measures, including urgent care; refers patients to specialists; makes independent decisions in relation to management and treatment of identified medical problems; performs various clinical procedures such as suturing, biopsy of skin lesions, and endometrial biopsy, usually with a written agreement with a collaborating physician; prescribes appropriate diet; provides information and counseling on health promotion, maintenance, illness prevention, social problems, and medication usage; evaluates the effectiveness of instruction and counseling; initiates and participates in research projects and studies; teaches groups of patients about health-related topics; provides outreach health education services in the community; serves as preceptor for nursing, nurse practitioner, medical, and physician assistant students; accepts after-hours calls and handles problems; participates in the development of pertinent health education and development of clinical practice guidelines; initiates and maintains follow-up on noncompliant patients (in nurse-managed health clinics, this function is usually performed by community outreach workers); makes patient home visits as necessary; makes hospital visits to patients and consults with other providers about patients who have been admitted to hospitals, home care, rehabilitation, or nursing homes; corresponds with insurers; manages patient care and develops treatment plans; assesses social and economic factors for each patient, tailoring care to those factors; tracks outcomes of interventions and alters them to achieve optimum results; obtains informed consent from patients; maintains familiarity with community resources and connects patients with appropriate resources; supervises and teaches registered nurses and non-licensed health care workers; participates in community programs, health fairs, schools and workplace programs; and represents the practice and profession at local, state, and federal government bodies and agencies. 
gree level, it is today. ${ }^{12}$ Requirements for NPs vary widely by state. Forty-two states require NPs to pass a national certification exam by a certifying agency such as the American Nurses Credentialing Center, the American Academy of Nurse Practitioners, and the National Certification Board of Pediatric Nurse Practitioners and Nurses. These three agencies require a master's degree, whereas the National Certification Corporation, which certifies Ob-Gyn and neonatal NPs, does not. ${ }^{12}$ It is perhaps the various state regulatory differences and the fact that not all NPs are prepared at the master's level that makes NPs vulnerable to criticism from some physicians.

In 2005, 346 colleges and universities offered NP master's degrees. The number has increased from 1998, when only 274 colleges and universities offered it. The increase in number of schools offering NP degrees reflects the local and national demand for NPs. ${ }^{12}$ In fact, it is estimated that the CCI will need to hire a minimum of $10,000 \mathrm{NPs}$ in the next few years to grow and expand the model of care. Recently, and not without debate within nursing, the major national nurse education associations have supported the implementation of a practice doctorate in nursing by the year $2015 .{ }^{14}$ Nurses with practice doctorates would be prepared and credentialed as independent practitioners just as other professional disciplines credential their providers: doctors of pharmacy, doctors of clinical psychology, and doctors of medicine. Nurses with practice doctorates would be fully accountable for their own practices and would collaborate with specialists of all kinds.

The average NP is female (95\%), 47 years old, has been in practice for 8.6 years, is a FNP $(35.1 \%)$, and is involved in direct care $(85.1 \%) .{ }^{15}$ Currently, NPs are in such high demand that most of them are employed upon graduation. The NP degree offers specialization within certain practice areas. The FNP degree is the most popular program, followed in prevalence by adult primary care, adult acute care/critical care, pediatrics, geriatrics, women's health care, psychiatric/mental health, and neonatal care. ${ }^{8}$ NPs with a family primary health care background are the most sought after by the CCI, because they are credentialed and licensed to care for patients of all ages.

\section{NP SCOPE OF PRACTICE, PRESCRIPTIVE AUTHORITY, AND PHYSICIAN RELATIONS}

NPs are APNs. They are sometimes called physician extenders and mid-level practitioners, which hinders the understanding of the NP role and CCCs. ${ }^{12}$ Physician extender is usually the term used by physician associations and medical publications when referring collectively to APNs. Some states, physician groups, and the federal Drug Enforcement Administration (DEA) use the term "mid-level practitioner."12 The DEA defines a mid-level practitioner "as an individual practitioner other than a physician, dentist, veterinarian, or podiatrist, who is licensed and registered, or otherwise permitted by the United States or the jurisdiction in which he/she practices to dispense controlled dangerous substances in the course of professional practice."16 Thus, the DEA considers NPs, nurse-midwives, nurse anesthetists, clinical nurse specialists, and PAs who are authorized to dispense controlled substances by the state in which they practice to be mid-level practitioners.

There has been some confusion as to the difference between a NP and a PA. PAs are educated in the medical model and their training is designed to complement physicians. ${ }^{12}$ PAs practice under the supervision of or in collaboration with a physician. ${ }^{17}$ In contrast, "NPs practice under their own license" and provide holistic care based on the nursing model. ${ }^{12}$

Since the early 1990s, many states have lessened or exempted the collaboration and/or supervisory relationship between NPs and physicians. Currently, there are 23 states (inclusive of the District of Columbia) that have no requirement for physician involvement, four states that require physician involvement but no requirement for written documentation of the relationship, and 24 states that require written documentation of physician involvement. ${ }^{18}$ States vary as to how they define scope of practice for NPs. In some states, the scope is enacted by the state legislature; in other states, boards of nursing have the authority to define the scope of practice. ${ }^{12}$

While NPs' permitted scope of practice and working relationship with the physician vary 
somewhat from state-to-state, NPs in general are capable and legally authorized to provide primary care to a patient that is comparable to that of a PCP. More than a decade ago, researchers determined that NPs were able to manage $80 \%-90 \%$ of the care provided to their patients without physician referral or consultation. ${ }^{19}$ Carolyn Buppert, a nurse-attorney, has argued that there is a need for clarity in the scope of practice for NPs. ${ }^{12}$ For example, the Pennsylvania wording of its scope of practice law: "while functioning in the expanded role as Registered Nurse, performs acts of medical diagnosis or prescription of medical therapeutics or corrective measures" gives NPs authority to diagnose and treat medical conditions and to write prescriptions. ${ }^{12}$ Carolyn Buppert argues that the "succinct Pennsylvania law provides more professional safety, than Oklahoma scope of practice law, for example, where 'a NP shall be eligible to obtain recognition as authorized by the Board to prescribe, as defined by rules and subject to the medical direction of a supervising physician.' "12

The lack of uniformity in the state definitions makes NPs vulnerable. ${ }^{1}$ The terms "independent," "collaboration," and "supervision" vary widely in interpretation and regulatory definition. ${ }^{20}$ The Joint Commission on Accreditation of Healthcare Organizations (JCAHO) defines a Licensed Independent Provider, as "any individual permitted by law and by the organization to provide care and services, without direction or supervision, within the scope of the individual's license and consistent with individually granted clinical privileges." Recent acknowledgement by JCAHO of NPs "offers support for hospital privileges based upon the NPs individual credentials, training, competency, and scope, rather than using the proxy of supervision as the primary eligibility requirement." 20

NPs now practice independently or in remote collaboration with physicians in 43 states, whereas only seven states require physician supervision. ${ }^{12}$ In all states, NPs have some level of independent authority to prescribe drugs. ${ }^{21}$ NPs are eligible for direct Medicaid reimbursement in every state and direct reimbursement for Medicare Part B services as part of the 1997 Balanced Budget Act. ${ }^{22}$

\section{PROVIDERS}

While many CCCs employ physicians and PAs as providers, this paper primarily focuses on CCCs staffed by NPs. There are approximately 141,000 NPs in the country, and almost half of the general public has seen a NP. Those who have been seen or treated by a NP report very high opinions of the quality of care they provided and their approach to providing that care. NPs, possessing advanced clinical skills and a strong desire to expand access to care, are identified as the ideal provider to deliver these needed services in this setting. Easily accessible and affordable, this health care model provides an entry point into the health care arena where NPs have the potential to triage patients to the needed level of care, advocate for a medical home for all patients, and reduce unnecessary visits to emergency rooms and Urgent Care Centers, in addition to diagnosing and treating common health problems.

NPs are nurses with advanced education and training whose scope of practice qualifies them to diagnose and treat medical conditions that are beyond the scope of the CCCs. NPs workings in this new innovative setting are more than qualified to handle the common conditions that are treated in these clinics. The foundation of the NP model of care is based on collaboration and patient advocacy. NPs in the CCC setting are in a position to reach patients who might not have sought traditional health care and direct them back into the health care system, to advocate for a medical home, and to work with the local health care provider community to ensure access to care.

In a CCC, the NP provides a limited scope of services. The NP in this setting focuses on taking care of everyday family illnesses such as strep throat, mononucleosis, ear infections, and rashes, while also providing patient education, health promotion and prevention services, and referring patients to an appropriate level of health care if necessary. Many clinics provide vaccinations, health screenings, and physicals. If a patient has a condition that falls outside of the provider's scope of practice and or the scope of the CCCs, the patient is referred back to his or her PCP or given direction as to where to get appropriate services for the illness. If a 
patient does not have a PCP, the CCI is committed to providing him or her with a referral list and advocating to the patient the need for a "PCP" and a "medical home." Most clinics have relationships with local physician groups, NPs, nurse-managed centers/practices, community clinics, and hospitals. Using these relationships, NPs can consult and refer patients who need immediate care and treatment regardless of their socioeconomic and health insurance status.

As this nascent industry begins its journey down the consumer-driven health care pathway, providers and consumers are raising pertinent questions. Providers want to know whether their scope of practice will be more restrictive than in other settings. Industry and nursing leaders conclude that they will not. States are tasked with determining scope of practice and that is not affected by where the provider works. Just as hospitals and clinics can modify policies to meet their needs, so too can the CCI. This latter group has decided that rather than offer a full scope of practice services, they will focus on the most common ailments that occur in family practice, while still providing quality education and innovative health promotion instructions. Practitioners will still be using their full armamentarium of skills, but rather than treat all illnesses, those that fall outside the advertised conditions will be referred to other appropriate health care providers.

Consumers, on the other hand, ask different questions. They want to know whether their health record can be shared with their PCP and whether they can use the CCC on a regular basis. The answer to both questions is "yes." Most clinics will eventually be able to share electronic records with the patient's PCP. However, until that time, a printed record can be given to the patient to share with their PCP. Continuity of care will be maintained in the best interest of the patient. It is possible for a patient to use the CCC on a regular basis if the illness falls within the scope of the clinic's advertised conditions and is not symptomatic of a serious condition. If so, they will be treated appropriately, and if not, they will be referred to a specialist. Either way, the industry provides both choice as well as access to quality care in a timely, cost-effective manner.

\section{HEALTH PROVIDER WORKFORCE SHORTAGE AND PROVIDER CHALLENGES}

Nursing's focus on people, its blend of medical, social science, and behavioral expertise, and its commitment to caring, counseling, teaching, and supporting patients are the characteristics that make nurses very qualified to provide primary care. ${ }^{8}$ Over the past three decades, states have adopted laws that authorize NPs to prescribe and provide primary care. The Institute of Medicine's broad definition of primary care is inclusive and not restrictive with regard to which profession can provide primary care. The definition was developed by a consensus group of providers, which included nurses, NPs, and physicians, and thus was not subject to bias from any one professional group. ${ }^{12}$ Most NPs work in collaboration with physicians, "but efforts to change licensing regulations to allow more independent practice have produced interprofessional clashes." 23

By 2010, the United States will experience a shortage of 50,000 physicians; this shortage is expected to rise to 200,000 physicians by 2020 . To meet the primary care needs of the US population, the American Academy of Family Physicians (AAFP) has estimated that residency programs need to graduate 3,700-4,100 family physicians per year. However, only 2,782 family physicians graduated in 2005 , and the number continues to decline. Currently, only $20 \%$ of third-year internal medicine residents are choosing careers as generalists. ${ }^{24}$ This decline in PCPs is partly due to increasing professional and educational emphasis on specialization. ${ }^{25}$ The decline is reinforced by the funding structure of Graduate Medical Education, which does not necessarily place funding in areas of need. Regardless of attempts to attract medical students into primary care, the decline in family physicians cannot be ignored, and thus supports the expansion of the CCC model.

Studies show that the proportion of patients seeing non-physician providers is growing, and the CCI is helping this trend. ${ }^{26}$ While states may have used physician shortages in underserved areas as a way to expand the scope of practice for NPs, recent studies have shown that patients treated by non-physician providers were more 
similar to than different from patients treated by physicians. ${ }^{26}$ Furthermore, there has been a significant "increase in the proportion of patients obtaining preventive services from nonphysician" providers. ${ }^{26}$ According to the Bureau of Labor Statistics, the annual number of new PA graduates is projected to fall $25 \%$ by 2020. While the number of NPs graduates is also declining, the rate is only by $4.5 \%$ every year. Approximately $80 \%$ of NPs practice in primary care, whereas only $44 \%$ of PAs currently practice in primary care. ${ }^{23}$ According to the AAFP, both NPs and PAs "remain important contributors to the primary care workforce and should not be neglected in workforce projections or in the designing of effective interdisciplinary teams." 27 PA and NP workforces have exploded during the past 15 years, and the AAFP, representing 94,000 family physicians, report that there are now, collectively, more NPs and PAs providing primary care than there are family physicians. ${ }^{28}$ Between 1987 and 1997, the proportion of patients who saw a non-physician provider rose from $30.6 \%$ to $36.1 \% .{ }^{26}$

\section{NP QUALITY CARE}

In 1986, a case study was released by the Office of Technology Assessment (OTA) in response to a request from the Senate Committee on Appropriations. ${ }^{29}$ The study assessed the contributions of NPs, nurse-midwives, and PAs in meeting the nation's health care needs. OTA concluded that the quality of care provided by NPs and physicians was equivalent. ${ }^{29}$ OTA concluded that potential heightened competition may decrease physicians' acceptance of NPs. ${ }^{29}$ While OTA and other studies conducted during the past two decades suggest the primary care delivered by NPs is equal to that of physicians, none of these studies have directly compared NPs and physicians in primary care health center practices that were similar both in terms of responsibilities and patient panels. ${ }^{21}$ Thus, a federally funded randomized trial was conducted by nurse and physician researchers at Columbia University between August 1995 and October 1997, "with patient interviews at 6 months after initial appointment and health services utilization data recorded at
6 months and 1 year after initial appointment." ${ }^{21}$ The study was designed to compare patient outcomes for NPs and physicians functioning equally as PCPs, within a conventional medical care framework in the same medical center, where all other elements of care were identical. The study concluded that of 1,316 primary care patients randomly assigned to either NPs or physicians in an ambulatory care situation, and where NPs had the same authority, responsibilities, productivity, administrative requirements, and patient population as PCPs, patients' outcomes were comparable. ${ }^{21}$ The results of the randomized controlled study "strongly supports the hypothesis that, using the traditional medical model of primary care, patient outcomes for NP and physician delivery of primary care do not differ." 21

While Mundinger concluded that the care of NPs and physicians functioning within the medical model is similar, no randomized trial has yet been conducted in nurse-managed centers, where NPs practice independently within a nursing model of primary care. Therefore, "to address the dearth of data and literature describing the full scope of services provided by nurse-managed health centers, the 2002 budget appropriation language for the Centers for Medicare and Medicaid Services (CMS) and the accompanying conference committee report included ... a demonstration project to evaluate nurse-managed health clinics in urban and rural areas across Pennsylvania, the state with the most nurse-managed clinics." 30 Specifically, the objectives of the evaluation were to "create an extensive descriptive evaluation of clients served and services provided in primary care nurse-managed health clinics; and to compare select population-based measures of quality and health care resource use to nurse-managed health clinics with those of like providers including community health clinics." 30

In response, an extensive descriptive evaluation was conducted at primary care nursemanaged health clinics in Pennsylvania, and select population-based measures of quality and health care resources were compared between nurse-managed health clinics and those of like providers, such as community health clinics. ${ }^{30}$ Patients were surveyed using the Medical Outcomes Trust Patient Satisfaction 
tool. Analysis of questions pertaining to patient access to health care and manner of health care delivered to patients by their primary care providers showed mean aggregate scores ranging from 4.03 to 4.19 on a five-point scale. Findings suggest that patients were satisfied with the accessibility and delivery of care at nurse-managed health clinics. ${ }^{31}$ This finding coincides with existing literature, which has shown that patients consistently have rated their satisfaction with care from NPs as high. Results showed that patients receiving care at nurse-managed health clinics experience significantly fewer emergency room visits, hospital inpatient days, specialist visits, and are at significantly lower risk of giving birth to low-birthweight infants compared to patients in conventional health care. ${ }^{31}$ These results suggest that nurse-managed health clinics reduce costs of health care through preventive health care.

\section{QUALITY CARE IN CCCS}

Quality care and quality assurance are critical to the long-term survival of the CCI. Thus, standardized protocols assist providers in clinical decision making at most CCCs. These protocols are used as a tool or guideline and are not intended to replace the critical thinking or the providers' clinical judgment, but to enhance and assist in the decision-making process. For example, the leading CCCs' guidelines are grounded in evidence-based medicine and guidelines published by the major medical bodies such as the American Academy of Pediatrics and the AAFP.

Most of the clinics are incorporating rigorous quality assessments into their evaluative structures. Both internal and external reviews are being built into these new entities; for example, formal chart review by collaborating physicians and peer-review by NPs with additional standard coding auditing. Credentialing of NPs and thorough work history is established as well as a process for ensuring adequate experience level to work in this new independent role. Most NPs are master's prepared and nationally certified in their specialty. CCCs strive to establish a referral base with physicians and other health care providers in the best interest of their patients, their NPs, and for the continuity of health care within the medical community. The CCI adheres to all state regulations regarding practice issues for the APN.

\section{HEALTH CARE PAYORS}

While the United States spends more annually on health care than any other country in the world, it still only ranks 37 of 191 in health system performance, according to the World Health Organization's 2000 evaluation of health systems worldwide. ${ }^{32}$ Most western countries have socialized medicine with minimal baseline health care coverage for all citizens. However, health care in the United States is still primarily employer based and provided through private health insurance programs. A new report from the Commonwealth Fund shows that $34 \%$ of Americans pay more than $\$ 1,000$ in out-of-pocket medical expenses due to coverage lapses, compared to $14 \%$ in Canada and Australia and $4 \%$ in the United Kingdom. ${ }^{33}$ The per capita purchasing parity power for the United States amounts to $14.6 \%$ of the gross domestic product. The rise in the number of uninsured from 38.7 million in 2000 to 45.6 million in 2002 to a projected 54 million in 2007 is associated with a growing number of smaller employers not offering health care benefits to their employees and their families. ${ }^{8}$ Currently, employer-sponsored health insurance provides coverage for 160 million Americans, reaching nearly three of every five of the non-elderly. With the costs of health care coverage increasingly shifting back on consumers and employees, the CCI is well positioned as an attractive, cost-effective alternative to often expensive and time-consuming emergency room visits.

Many CCI companies have contracts with insurance companies and health plans, resulting in the patient only being charged a co-pay for a visit to a clinic. The CCI has had strong interest from employers who are self-insured. All Americans would like to reduce health care costs, which are expected to be $\$ 1$ for every $\$ 5$ spent in this country by 2015 . Some insurers are actively encouraging patients to use CCCs by lowering the co-pay. For those companies that 
accept insurance plans, the cost of health care can be reduced because the cost of services at CCCs is far less expensive than other health care options (eg, the emergency room) for identical conditions. A recent cost comparison of treating a patient for strep throat showed that retail-based clinics were the most cost-effective and emergency departments the most expensive. ${ }^{2}$ For small businesses, regardless of insurance coverage, the easy access of a visit to a CCC can reduce the time away from work to receive care. The affordability of a visit to a CCC encourages patients to receive care early on, which could help prevent lengthy and costly absences from work and could result in the early identification and treatment of conditions that might otherwise have resulted in delayed treatment and poor outcomes.

"The key to NPs unequivocal market access rests in the ability to bill third-party insurers independently and receive equitable pay for their services." 8 Although the managed care model began among commercial insurance plans, state governments trying to control rising Medicaid costs have passed laws and regulations in the past decade to promote the spread of managed care among publiclyfunded health care programs as well. According to a 2005 report from the Centers for Medicare and Medicaid Services, thirty-nine states have shifted the majority of their Medicaid beneficiaries into managed care plans. ${ }^{34}$ In 2004, 163 million people in the United States were enrolled in commercial insurance plans ${ }^{35}$; $90 \%$ of those people received their health benefits through a managed care plan. ${ }^{36}$

To date, $40 \%$ of CCI companies are contracted as service providers with managed care organizations. Thus, a challenge to CCI growth and expansion lies in its ability to continue to grow reimbursement from managed care plans. For example, to date only $33 \%$ of managed care companies have a uniform policy allowing NPs to be credentialed as PCPs. Approximately $40 \%$ of Medicaid managed care companies credential NPs despite the 1997 Balanced Budget Act, which strongly supports the inclusion of NPs on health insurance plans. Among plans that admit NPs to their networks, only $52 \%$ reimburse them at the same rate as
PCPs. ${ }^{37}$ The Balanced Budget Act of 1997 (BBA, P.L. 105-33) encouraged states to move Medicaid recipients into managed care and to use primary care case managers as gatekeepers in feefor-service. However, despite congressional intent, it failed to fully recognize APNs, particularly NPs, as participants in these plans. While the Act encouraged states to ensure that NPs and other APNs are included in managed care provider panels, the fact that only $40 \%$ of Medicaid managed care companies include NPs shows that this policy has largely been a failure. The most popular reason for not credentialing NPs is weak state laws, which do not require managed care companies to credential NPs. ${ }^{37}$

As more sophisticated companies emerge in the CCI, coupled with strong consumer demand, it is expected that contracts between CCCs and payors will increase rapidly. In many cases, CCCs already have contracts covering over $90 \%$ of insured lives in their respective markets.

\section{CONCLUSION}

CCCs have evolved at a time when our health care system is floundering. The focus of the CCI is quality, convenience, and consumer choice. They have established standards, employ competent professional health care providers, and use ongoing quality improvement mechanisms including the incorporation of evidence-based practices in the care of their patients. Health care delivery systems are changing in multifaceted ways and are constantly in flux. CCCs have identified the need for change and are filling a niche by moving to bridge the chasm between a failing health care system and a rising new model of care that offers highquality, cost-effective, and timely health care.

\section{REFERENCES}

1. Malvey D, Fottler M. The retail revolution in health care: who will win and who will lose? Health Care Manage Rev 2006;31:168-178.

2. Scott M. Health care in the express lane: the emergence of retail clinics. California HealthCare Founda- 
tion website. Available at: www.chef.org/topics/ view.cfm?itemID=123218. Accessed October 10, 2006.

3. Matherlee $\mathrm{K}$. The nursing center in concept and practice: delivery and financing issues in serving vulnerable people. National Health Policy Forum website. Available at: www.nhpf.org/pdfs_ib/IB746_Nurs Center_9-13-99.pdf. Accessed October 10, 2006.

4. Gullo K. Many agree on potential benefits of onsite clinics in major retail stores that can provide basic medical services, yet large numbers are also skeptical. The Wall Street Journal Online website. Available at: www.harrisinteractive.com/news/newsletters / wsjhealthnews /WSJOnline_HI_Health-CarePoll 2005vol4_iss21.pdf. Accessed October 10, 2006.

5. American Academy of Pediatrics. AAP principles concerning retail-based clinics. Available at: www. aap.org/advocacy / releases / rbc.pdf\#search=\%22am erican $\% 20$ academy $\% 20$ of $\% 20$ pediatrics $\% 20$ principles\%22. Accessed October 10, 2006.

6. Alliance of Advanced Practice Nurses, Policy Brief. Advanced practice nurses perform full scope of practice: an action agenda for the Commonwealth of Pennsylvania. [On file with the Pennsylvania State Nurses Association.] 2005.

7. Grumbach K, Hart L, Mertz E, Coffman J, Palazzo L. Who is caring for the underserved?: a comparison of primary care physicians and non-physician clinicians in California and Washington. Ann Fam Med 2003;1:97-104.

8. Mezey M, McGivern D, Sullivan-Marx E, Greenberg S, eds. Nurse practitioners: evolution of advanced practice, $4^{\text {th }}$ ed. New York: Springer: 2003.

9. Ford L. Nurse practitioners: the evolution of primary care. J Nurs Scholarsh 1986;18:177-178.

10. Institute of Medicine. Defining primary care: an interim report. Washington, DC: National Academies Press, 1994.

11. Buppert C. What does the Supreme Court's ruling on the Kentucky Any Willing Provider Law mean for NPs? Nurse Practitioner World News 2003;3:3-5.

12. Buppert C. Nurse practitioner's business practice and legal guide, $2^{\text {nd }}$ ed. Sudbury, MA: Jones \& Bartlett Publishers, 2004.

13. U.S. Department of Health and Human Services. The registered nurse population: findings from the $2000 \mathrm{Na}-$ tional Sample Survey of Registered Nurses. Available at: http://bhpr.hrsa.gov/healthworkforce/reports / rnsurvey/rnss1.htm. Accessed October 10, 2006.

14. Glazer G. Overview and summary: the doctor of nursing practice: the need for more dialogue. Available at: www.nursingworld.org/ojin/topic28/tpc28ntr.htm. Accessed October 10, 2006.

15. American Association of Nurse Practitioners. Nurse practitioner demographics. Available at: www.aanp. org / About + AANP / Marketing + and + PR/NP+Demographics.htm. Accessed October 10, 2006.

16. 21 C.F.R. $\$ 1300.01$ (2005).

17. American Academy of Physician Assistants. Information about PAs and the PA profession. Available at: www.aapa.org/geninfo1.html. Accessed October 10, 2006.

18. Pearson L. The Pearson report. Am J Nurse Pract 2005;10:25.

19. Mundinger MO. Advanced practice nursing-good medicine for physicians? N Engl J Med 1994;330: 211-214.

20. Medscape. Business of medicine. Scope of practice and the nurse practitioner. Available at: www.medscape.com/viewarticle/506277_5. Accessed October 10, 2006.

21. Mundinger MO, Kane RL, Lenz ER, et al. Primary care outcomes in patients treated by nurse practitioners or physicians: a randomized trial. JAMA 2000;283:59-68.

22. Balanced Budget Act, Pub. L. No. 105-33 (1997).

23. American Academy of Family Physicians. Renewed debate: is there a physician shortage? Available at: www.aafp.org/fpm/20020300/monitor.html. Accessed October 10, 2006.

24. Bodenheimer T. Primary care-will it survive? N Engl J Med 2006;355:861-864.

25. Pugno PA, Schmittling GT, Fetter GT Jr, Kahn NB Jr. Results of the 2005 national resident matching program: family medicine. Fam Med 2005;37:555-564.

26. Druss BG, Marcus SC, Olfson M, Tanielien M, Pincus HA. Trends in care by nonphysician clinicians in the United States. N Engl J Med 2003;348:130-137.

27. American Academy of Physician Assistants. Trends in the physician assistant profession 1991-2003. Available at: www.aafp.org/afp/20051001/graham.html. Accessed October 10, 2006.

28. Green L, Dodoo M, Ruddy G, et al. The physician workforce of the United States: a family medicine perspective. The Robert Graham Center website. Available at: www.graham-center.org/PreBuilt/physician_workforce.pdf\#search $=\% 22$ The $\% 20$ Physician $\%$ 20Workforce $\% 20$ of $\% 20$ the $\% 20$ United $\% 20$ States $\% 3 \mathrm{~A}$ $\% 20$ A $\% 20$ Family $\% 20$ Medicine $\% 20$ Perspective $\% 22$. Accessed October 10, 2006.

29. Safriet BJ, Health care dollars and regulatory sense: the role of advanced practice nursing. Yale J Regul 1992;9:417-488.

30. Hansen-Turton T. The nurse-managed health center safety net: a policy solution to reducing health disparities, $1^{\text {st }}$ ed. New York: Elsevier-Saunders, 2006.

31. Hansen-Turton T, Line L, O'Connell M, Rothman N, Lauby J. Report to the Centers for Medicare and Medicaid Services: the nursing model of health care for the underserved. Available at: www.nncc.us/programs /CMS\%20Revised-Section1(CovTitleAck)-Submitted120604.doc. Accessed October 10, 2006.

32. World Health Organization. The world health report 2000; health systems-improving performance. Available at: www.who.int/whr/2000/en/whr00_en.pdf. Accessed October 10, 2006.

33. Anderson GF, Hussey PS, Frogner BK, Waters HR. Health spending in the United States and the rest of the industrialized world. Health Aff (Millwood) 2005;24:903-914. Available at: www.cmwf.org/publi- 
cations /publications_show.htm?doc_id $=283969$. Accessed October 10, 2006.

34. Centers for Medicare and Medicaid Services. Medicaid managed care enrollment as of December 31, 2004. [On file with National Nursing Centers Consortium, Philadelphia, PA.] 2004.

35. Waller R. Interstudy competitive edge: Part II, HMO industry report, fall 2004. Nashville, TN: Interstudy Publications, 2004.

36. Rich RF, Erb CT. The two faces of managed care regulation and policymaking. Stanford Law Pol Rev 2005;16:234-276.
37. Hansen-Turton T, Ritter A, Rothman N, Valdez B. Insurer policies create barriers to healthcare access and consumer choice. Nurs Econ 2006;24:204-211.

Address reprint requests to: Tine Hansen-Turton, M.G.A. National Nursing Centers Consortium 260 South Broad St., $18^{\text {th }} \mathrm{Fl}$. Philadelphia, PA 19102

E-mail: tine@mncc.us 